\title{
How to gain evidence in neurorehabilitation: a personal view
}

\author{
Luft, A R
}

\begin{abstract}
Abstract Neurorehabilitation is an emerging field driven by developments in neuroscience and biomedical engineering. Most patients that require neurorehabilitation have had a stroke, but other diseases of the brain, spinal cord, or nerves can also be alleviated. Modern therapies in neurorehabilitation focus on reducing impairment and improving function in daily life. As compared with acute care medicine, the clinical evidence for most neurorehabilitative treatments (modern or conventional) is sparse. Clinical trials support constraint-induced movement therapy for the arm and aerobic treadmill training for walking, both high-intensity interventions requiring therapist time (i.e., cost) and patient motivation. Promising approaches for the future include robotic training, telerehabilitation at the patient's home, and supportive therapies that promote motivation and compliance. It is argued that a better understanding of the neuroscience of recovery together with results from small-scale and well-focused clinical experiments are necessary to design optimal interventions for specific target groups of patients.
\end{abstract}

DOI: https://doi.org/10.1515/bmt-2011-0135

Posted at the Zurich Open Repository and Archive, University of Zurich

ZORA URL: https://doi.org/10.5167/uzh-66963

Journal Article

Accepted Version

Originally published at:

Luft, A R (2012). How to gain evidence in neurorehabilitation: a personal view. Biomedizinische Technik. Biomedical engineering:1-7.

DOI: https://doi.org/10.1515/bmt-2011-0135 


\section{How to gain evidence in neurorehabilitation - A personal view}

Andreas R. Luft

Department of Neurology, University of Zurich, Switzerland

Frauenklinikstrasse 26

$\mathrm{CH}-8091$ Zürich

Switzerland

ph: +4144255 5400

fax: +41442554649

eMail: andreas.luft@uzh.ch

Running Title: Stroke Rehabilitation 


\begin{abstract}
Neurorehabilitation is an emerging field driven by developments in neuroscience and biomedical engineering. Most patients that require neurorehabilitation had a stroke, but also other diseases of brain, spinal cord or nerves can be alleviated. Modern therapies in neurorehabilitation focus on reducing impairment and improving function in daily life. As compared with acute care medicine, the clinical evidence for most neurorehabilitative treatments (modern or conventional) is sparse. Clinical trials support constraint-induced movement therapy for the arm and aerobic treadmill training for walking, both high intensity interventions requiring therapist time (i.e. cost) and patient motivation. Promising approaches for the future include robotic training, telerehabilitation at the patient's home, and supportive therapies that promote motivation and compliance. We argue that a better understanding of the neuroscience of recovery together with results from small scale and well-focused clinical experiments are necessary to design optimal interventions for specific target groups of patients.
\end{abstract}

\title{
Introduction
}

In the conventional view, rehabilitation starts when and where acute care medicine has left the patient with a disability. The aim of rehabilitation is to reintegrate the patient into his or her professional life, social life and home environment. This aim can be achieved by different approaches: by providing assistive devices, making adjustments to life or home or by reducing individual impairments. Neurorehabilitation treats patients with brain disorders, most often with stroke, because it is frequent and frequently leads to neurological sequelae. After a stroke event a patient typically recovers unless another stroke interferes. This is in contrast to diseases with a slowly progressive (e.g. Parkinson's disease) or undulating time course (e.g. multiple sclerosis). But, stroke recovery is a slow process lasting months or years.

If one aims at fast reintegration and wants to minimize rehabilitation costs, assisting (nursing), modifying the environment or training the patient to compensate for disability - e.g. training to eat or dress with the good arm when the other one is impaired - is often chosen. This leaves the patient with an impairment that reduces his or her quality of life. Also cost reduction is short-sighted - in the 
long run functional impairments put the patient at higher risk for complications that may cost much more then the rehabilitation upfront.

Modern neurorehabilitation aims at reducing impairments and gaining function. This requires time and training of sufficient intensity [1-4]. If performed intensely, most treatments that involve active training provide similar benefits across groups [5]. But, the response of individual patients varies largely. Little is known about the factors that determine therapy response. While small scale studies show effects of lesion location, side or the timing of therapy relative to the stroke [6], larger trials are necessary to confirm these findings.

While many decisions in acute care medicine can be based on scientifically sound evidence from clinical trials, only few trials exist for stroke rehabilitation. Those that are available were conducted in small patient groups, few hundreds of individuals at most [7]. This level of evidence compares poorly to trials testing, for example, the use of thrombolysis for acute stroke that recruited several hundreds to thousands of patients $[8,9]$.

This article does not aim at providing a complete overview of stroke rehabilitation but formulates an opinion about how the field can develop in the coming years.

\section{Evidence of benefit}

\section{Training interventions without technical assistance}

Despite these difficulties there is sufficient evidence to assume that a few treatments are effective. Two examples are constraint induced movement therapy (CIMT) and aerobic treadmill exercise. CIMT is based on the neuroscientific observation that immobility leads to deficits [10]. If a stroke survivor does not use the arm due to weakness, the arm will deteriorate further. Therefore CIMT forces stroke survivors to use the weak arm by immobilizing the intact arm. This, of course, only works if subjects have good residual arm function. If one cannot move the arm at all, immobilizing the other arm will be frustrating. In addition, CIMT includes an intensive (usually two hours per day) physical therapy protocol which trains movements by reinforcing goal-directed behavior in a stepwise fashion (shaping). The latter component - or the fact that it is delivered in an intensity higher than standard physical therapy protocols - may be more important than immobilization itself [11]. CIMT has been 
shown to be more effective in reducing impairment and improving arm function than standard rehabilitation protocols $[12,13]$. However, one must consider that comparing an intervention to "standard rehabilitation" carries the disadvantage of poor generalizability because the "standard" differs greatly between institutions, countries, continents. Also, the standard is often insufficiently described in study reports to arrive at generalizable conclusions.

Another form of effective motor therapy is treadmill training. Walking on a treadmill is a task-oriented highly repetitive form of training that carries over to better walking over ground [14]. Treadmill training with body weight support can be performed early after the stroke and seems to be equally effective as a home-based physical therapy program [15]. Treadmill training works through inducing changes in brain activation related to knee movement [16], an indication of reorganization within CNS circuits. It also changes the composition of skeletal muscle thereby potentially improving insulin resistance and type II diabetes [17-19]. If performed at a sufficient intensity to increase heart rate, aerobic treadmill training also has a conditioning effect thereby improving cardiorespiratory fitness even in patients with very low fitness levels $[16,20,21]$. Thus, this form of training serves several objectives: it not only trains walking but equips the patients with better fitness to effectively walk in daily life and reduces diabetes as a major risk factor for future strokes [22].

\section{Training interventions with technical assistance}

Neurorehabilitation engineering is an expanding field and has produced many interesting devices to aid rehabilitative training. However, few have been test in larger groups of patients. Weight supported treadmill training uses a harness to reduce the body weight while the patient walks on a treadmill [14]. Several clinical trials were conducted after stroke; a Cochrane metaanalysis of trials describes a modest effect in people who could walk independently [23]. Results in patients after spinal cord injury are conflicting because studies are too heterogeneous to be compared $[24,25]$. The widespread use of these interventions remains disputed [26]. 


\section{Promising technical developments}

\section{Sensors and monitoring}

Neurorehabilitation science needs to improve its methods, specifically, how to optimally and reliably measure therapy effects. First, researchers have to agree on the purpose of therapy. The international classification of function proposes a trichotomy of therapy goals: (1) to reduce impairment, (2) to regain functional use, (3) to enable participation in life. From one to three, these objectives become more difficult to achieve because a multitude of co-factors intervene. If an impairment, e.g., spasticity is reduced, it does not necessarily mean that the patient can use the arm to eat. If the patient is trained to use the fork with the weak arm, it does not mean that she/he will actually do so in daily life, i.e., participate. It will be interesting to measure the effects of a therapy on participation. Participation is difficult to measure because it requires patient monitoring in the natural environment (home, work etc.). Sensor technologies measuring location, acceleration, rotation, altitude, heart rate, muscle activity, interaction forces etc. combined with storage and analytical capabilities may be able to deliver this information. Simple accelerometry is useful for activity monitoring in stroke survivors [27]. Combining accelerometers and gyroscopes can classify activities at least into broad categories of standing, sitting, lying and walking $[28,29]$. Gait and balance can be monitored using accelerometry sensors on the pelvis [30] or inertial sensors and force sensors in the shoes [31,32]. For the upper extremity, sensing of reach ing movements have been performed using textile integrated sensing systems [33]. These data can then be used to optimize a therapy for the individual patient.

\section{Robots}

Robotic devices have originally been developed to assist physical and occupational therapists in movement training [34]. Especially, highly repetitive training like walking on a treadmill with the therapist moving the weak leg is facilitated by a robot. But, theoretically robots can do more. By precisely monitoring the patients movement, they can interfere with it at the right time and place. This robot-human interaction can be in the form of assistance, that is, to complete a movement that the patient cannot fully perform. Assistance or guidance has been shown to improve motor skill acquisition [35] but may also impair the acquisition of tasks that highly depend on error-based learning [36,37]. The devices include end-effector based robotic manipulandums [38,39] or 
exosceletons [40]. Assist-as-needed robotic training has been tested in a clinical trial and has been found not to be superior to conventional physical therapy [7]. In spinal cord injury, the efficacy of assist-as-needed training has been suggested by animal models [41,[NO STYLE for: Cai 2005]] and human studies $[43,44]$. Robot-human interaction can also mean that the robot perturbs the patients movement, e.g., by applying a force that deviates from the desired movement path $[45,46]$. Because perturbation renders a movement more difficult, it delivers a stronger learning stimulus that may support recovery $[47,48]$. Both elements of robotic training, assistance and perturbation, have not been fully tested in humans after stroke. Based on motor learning theory, one would expect more benefit from perturbation than from assistance [49].

Another element of robotic arm therapy is proximal support. Proximal support of the arm facilitates distal movements [50]. This concept - part of the Brunnstrom stages of motor recovery - has been successfully integrated into robotic training. Stepwise loading of the arm proximally helps to increase the range of motion across the elbow [50]. The range of motion increases the work area of the arm thereby helping to overcome thresholds necessary for daily life tasks [51].

Another element of robotic training is to stimulate strength and muscle force. Strength training is beneficial for motor recovery after stroke [52]. While simpler, non-robotic devices are available to enable muscle training, robots may be specifically useful for integration of strength into task-oriented training.

\section{Rehabilitation at home}

Training can be more efficient if delivered at high intensity (long duration and greater complexity of motor exercises) as long as it is not limited by motivation or fatigue $[1,53,54]$. High intensity training is costly and often not feasible because the patient needs be admitted as inpatient of is required to travel to a rehabilitation center frequently for outpatient training. Therefore new approaches to rehabilitation at home are needed. Training at home by a rehabilitation therapist is often practiced and useful $[55,56]$. Computer assisted gaming can provide assistance, supervision and motivational feedback to enable effective training at home. Commercially available products have been used and found feasible and safe for stroke survivors at home $[57,58]$. Even video-based training has been proposed [59]. Potential problems are the price of the equipment, mal-compliance, poor ergonomics 
of use and the lack of immediate expert feedback if training is conducted in the wrong way. Depending on the system and on the focus of rehabilitation (e.g. arm, leg), the patient's home needs to fulfill certain requirements (e.g. minimum space, internet connection etc). But, modern computer technology provides low-cost and high-quality equipment to render home-rehabilitation a realistic option for the future.

\section{Motivational therapy}

Motivation is a prerequisite to successful therapy. Therapists need to engage and motivate the patient to be successful. One factor that stimulates motivation is positive feedback and reward. Reward is in part encoded within the dopaminergic networks of basal brain regions such as substantia nigra and ventral tegmental area [60]. These regions also send projections to primary motor cortex where dopamine supports the acquisition of a motor skill as well as the formation of synaptic plasticity, that is, a cellular mechanism of learning $[61,62]$. It is therefore likely that reward signals are directly fed into motor cortex networks to support learning. It remains to be shown that the effects of specific rehabilitative training can be augmented by emphasizing rewards or by medications that facilitate dopamine actions. Preliminary evidence suggests a role of levodopa in supporting physiotherapy in stroke survivors [63]. Training schemes may pay spcific attention to being rewarding and motivational. Promising approaches are music therapy [64] and virtual reality training [57] or rehabilitation gaming [65]. Further research is necessary to elucidate the neuroscience and potential clinical applications behind motivation-enhancing strategies as an add-on to movement training.

\section{Why is there little evidence in neurorehabilitation?}

There are many reasons why the evidence level in stroke neurorehabilitation is poor.

1. The problem is complex. The stroke survivor faces a plethora of problems: deficits of movement, language and communication, mobility and fitness, cognition and emotion as well as social issues. It is obvious that each of these require different and likely individualized treatment approaches. However, single treatments need to be developed and tested separately in smaller trials before they can be combined into a universal rehabilitative program. An alternative solution is to carefully select a homogeneous sample of patients with specific deficits or lesions to be included in trials. However, 
this carries the disadvantage that results are unlikely to generalize to larger populations and that the study cannot address questions about correlations between therapy response and, e.g., lesion location of deficit severity.

2. While the overall aim of all therapies taken together is to improve the patient's functioning and independence, it is unclear what specific outcome measure to use in order to prove that a single therapy works. A therapy aiming, for example, at improving elbow movement can only be expected to do exactly that, i.e., improving the elbow [5]. It cannot be expected to increase quality of life (QoL) or independence because more than elbow function is needed to achieve this goal. Using elbow movement as an endpoint measure of a trial investigating elbow therapy - even there is debate what should actually be measured - is often criticized as being meaningless for the patient. While this is true from a global perspective, substituting the elbow measure with a more global assessment will render the trial negative. As a consequence the therapy is no longer investigated or utilized. Therapies aiming to improve QoL will have to consist of different therapies addressing all functional domains that are impaired in an individual patient. A collection of single interventions is extremely difficult or impossible to standardize between cases.

3. It is difficult to formulate valid comparisons for randomized trials. While a pill can be compared to a placebo pill using a double-blinded design, blinding is difficult in neurorehabilitation. Comparisons of two treatments, e.g., a new therapy robot to conventional therapy, can be criticized: Patients may be more impressed by expensive robotic equipment than by a conventional physical therapist, or they may like the therapist more than the non-human robot - both settings that will induce large placebo effects. Valid comparisons are needed to identify training strategies that work better than others and in whom, i.e., in which patient population.

4. Neurorehabilitative treatment in most cases involves many hours of training hours requiring high compliance of patients and therapists alike. This translates into cost. Clinical trials are expensive and are even more so if the investigational therapy is costly. On the other hand, funding for neurorehabilitation trials is scarce because there are few large companies - like the pharmaceutical industry - with an interest in neurorehabilitative interventions. Public funding for neurorehabilitation trials is insufficient. 
5. There is too little basic understanding of recovery mechanisms. Before a drug is tested in a clinical trial, exact knowledge exists about its mode of action, dosage, pharmacokinetics etc. In neurorehabilitation, the threshold dosage (intensity) of a treatment that is required to produce an effect is seldom known, left alone how the treatment works. More neuroscience is required to pave the way for successful neurorehabilitative interventions.

\section{Summary}

Technical developments may not only show the way towards novel therapeutic approaches but provide excellent research tools to test hypothesis relevant for therapy development and optimization. Important hypotheses to be tested are what strategies of training, e.g., perturbation, motivation, assistance, repetition, are more beneficial than others? What strategies work best in which patient population? At what time after the stroke should these therapies be applied and in which dose?

In neurorehabilitation there is little evidence on the efficacy of interventions. Versatile treatment options are available but they all seem to provide similar benefits if delivered at sufficient intensity. Nevertheless the treatment response varies greatly between individuals. It seems likely that certain (unknown) factors predispose a patient to treatment success, that different individuals will require different therapies and that treatment plans need to be tailored to optimize the individual's response. A well characterized therapeutic instrumentarium will therefore be necessary. Novel sensor technologies can provide powerful assessment instruments to measure not only motor impairment and function but also how the patient moves in daily life. Neurorehabilitation technology to improve training carries a great potential but probably is still used in suboptimal ways and, therefore, cannot demonstrate superiority to conventional approaches. Optimal strategies can only be developed if a thorough understanding of the neuroscience of recovery is achieved. Based on this knowledge, therapeutic concepts can be derived that require testing in smaller clinical experiments before large scale clinical trials can yield interpretable results (Fig. 1). 


\section{References}

1. Wolf SL, Newton H, Maddy D, et al. The Excite Trial: relationship of intensity of constraint induced movement therapy to improvement in the wolf motor function test. Restorative neurology and neuroscience. 2007;25:549-62.

2. Teasell R, Bitensky J, Salter K, Bayona NA. The role of timing and intensity of rehabilitation therapies. Top Stroke Rehabil. 2005;12:46-57.

3. Sivenius J, Pyorala K, Heinonen OP, Salonen JT, Riekkinen P. The significance of intensity of rehabilitation of stroke--a controlled trial. Stroke. 1985;16:928-31.

4. Kwakkel G, van Peppen R, Wagenaar RC, et al. Effects of augmented exercise therapy time after stroke: a meta-analysis. Stroke. 2004;35:2529-39.

5. Van Peppen RP, Kwakkel G, Wood-Dauphinee S, Hendriks HJ, Van der Wees PJ, Dekker J. The impact of physical therapy on functional outcomes after stroke: what's the evidence? Clin Rehabil. 2004;18:833-62.

6. Lam JM, Globas C, Cerny J, et al. Predictors of Response to Treadmill Exercise in Stroke Survivors. Neurorehabil Neural Repair. 2010;24:567-74.

7. Lo AC, Guarino PD, Richards LG, et al. Robot-Assisted Therapy for Long-Term Upper-Limb Impairment after Stroke. The New England journal of medicine. 2010;362:1772-83.

8. Hacke W, Kaste M, Bluhmki E, et al. Thrombolysis with alteplase 3 to 4.5 hours after acute ischemic stroke. The New England journal of medicine. 2008;359:1317-29.

9. Sandercock P, Lindley R, Wardlaw J, et al. Update on the third international stroke trial (IST-3) of thrombolysis for acute ischaemic stroke and baseline features of the 3035 patients recruited. Trials. $2011 ; 12: 252$

10. Taub E, Uswatte G, Elbert T. New treatments in neurorehabilitation founded on basic research. Nature reviews Neuroscience. 2002;3:228-36. 
11. Brogårdh C, Vestling $M$, Sjölund BH. Shortened constraint-induced movement therapy in subacute stroke - no effect of using a restraint: a randomized controlled study with independent observers. J Rehabil Med. 2009;41:231-6.

12. Wolf SL, Winstein CJ, Miller JP, et al. Effect of constraint-induced movement therapy on upper extremity function 3 to 9 months after stroke: the EXCITE randomized clinical trial. JAMA. 2006;296:2095-104.

13. Sirtori V, Corbetta D, Moja L, Gatti R. Constraint-induced movement therapy for upper extremities in stroke patients. Cochrane database of systematic reviews (Online). 2009:CD004433.

14. Hesse S. Treadmill training with partial body weight support after stroke: a review. NeuroRehabilitation. 2008;23:55-65.

15. Duncan PW, Sullivan KJ, Behrman AL, et al. Body-weight-supported treadmill rehabilitation after stroke. The New England journal of medicine. 2011;364:2026-36.

16. Luft AR, Macko RF, Forrester LW, et al. Treadmill exercise activates subcortical neural networks and improves walking after stroke: a randomized controlled trial. Stroke; a journal of cerebral circulation. 2008;39:3341-50.

17. Hafer-Macko CE, Ryan AS, Ivey FM, Macko RF. Skeletal muscle changes after hemiparetic stroke and potential beneficial effects of exercise intervention strategies. Journal of rehabilitation research and development. 2008;45:261-72.

18. Ivey FM, Ryan AS, Hafer-Macko CE, Goldberg AP, Macko RF. Treadmill aerobic training improves glucose tolerance and indices of insulin sensitivity in disabled stroke survivors: a preliminary report. Stroke; a journal of cerebral circulation. 2007;38:2752-8.

19. Ivey FM, Ryan AS, Hafer-Macko CE, Goldberg AP, Macko RF. Treadmill Aerobic Training Improves Glucose Tolerance and Indices of Insulin Sensitivity in Disabled Stroke Survivors. A Preliminary Report. Stroke. 2007; published online. 
20. Macko RF, Ivey FM, Forrester LW, et al. Treadmill exercise rehabilitation improves ambulatory function and cardiovascular fitness in patients with chronic stroke: a randomized, controlled trial. Stroke; a journal of cerebral circulation. 2005;36:2206-11.

21. Globas C, Becker C, Cerny J, et al. Chronic stroke survivors benefit from high-intensity aerobic treadmill exercise: a randomized control trial. Neurorehabil Neural Repair. 2012;26:85-95.

22. Goldstein LB, Bushnell CD, Adams RJ, et al. Guidelines for the primary prevention of stroke: a guideline for healthcare professionals from the American Heart Association/American Stroke Association. Stroke; a journal of cerebral circulation. 2011;42:517-84.

23. Moseley AM, Stark A, Cameron ID, Pollock A. Treadmill training and body weight support for walking after stroke. Cochrane database of systematic reviews (Online). 2003:CD002840.

24. Lucareli PR, Lima MO, Lima FP, de Almeida JG, Brech GC, D'Andréa Greve JM. Gait analysis following treadmill training with body weight support versus conventional physical therapy: a prospective randomized controlled single blind study. Spinal Cord. 2011;49:1001-7.

25. Dobkin B, Apple D, Barbeau $H$, et al. Weight-supported treadmill vs over-ground training for walking after acute incomplete SCI. Neurology. 2006;66:484-93.

26. Dobkin BH, Duncan PW. Should body weight-supported treadmill training and robotic-assistive steppers for locomotor training trot back to the starting gate? Neurorehabil Neural Repair. 2012;26:308-17.

27. Gebruers N, Vanroy C, Truijen S, Engelborghs S, De Deyn PP. Monitoring of physical activity after stroke: a systematic review of accelerometry-based measures. Archives of physical medicine and rehabilitation. 2010;91:288-97.

28. Veltink PH, Bussmann HB, de Vries W, Martens WL, Van Lummel RC. Detection of static and dynamic activities using uniaxial accelerometers. IEEE Trans Rehabil Eng. 1996;4:375-85.

29. Jeannet PY, Aminian K, Bloetzer C, Najafi B, Paraschiv-lonescu A. Continuous monitoring and quantification of multiple parameters of daily physical activity in ambulatory Duchenne muscular dystrophy patients. Eur J Paediatr Neurol. 2011;15:40-7. 
30. Zijlstra W, Hof AL. Assessment of spatio-temporal gait parameters from trunk accelerations during human walking. Gait Posture. 2003;18:1-10.

31. Martin Schepers $H$, van Asseldonk EH, Baten CT, Veltink PH. Ambulatory estimation of foot placement during walking using inertial sensors. J Biomech. 2010;43:3138-43.

32. Mariani B, Hoskovec C, Rochat S, Büla C, Penders J, Aminian K. 3D gait assessment in young and elderly subjects using foot-worn inertial sensors. J Biomech. 2010;43:2999-3006.

33. Tognetti A, Bartalesi R, Lorussi F, De Rossi D. Body segment position reconstruction and posture classification by smart textiles. Transactions of the Institute of Measurement and Control. 2007;29:215-53.

34. Hesse S, Schmidt H, Werner C, Bardeleben A. Upper and lower extremity robotic devices for rehabilitation and for studying motor control. Curr Opin Neurol. 2003;16:705-10.

35. Marchal Crespo L, Reinkensmeyer DJ. Haptic guidance can enhance motor learning of a steering task. J Mot Behav. 2008;40:545-56.

36. Domingo A, Ferris DP. Effects of physical guidance on short-term learning of walking on a narrow beam. Gait Posture. 2009;30:464-8.

37. Winstein CJ, Pohl PS, Lewthwaite R. Effects of physical guidance and knowledge of results on motor learning: support for the guidance hypothesis. Res Q Exerc Sport. 1994;65:316-23.

38. Krebs HI, Ferraro M, Buerger SP, et al. Rehabilitation robotics: pilot trial of a spatial extension for MIT-Manus. J Neuroeng Rehabil. 2004;1:5.

39. Lambercy O, Dovat L, Gassert R, Burdet E, Teo CL, Milner T. A haptic knob for rehabilitation of hand function. IEEE Trans Neural Syst Rehabil Eng. 2007;15:356-66.

40. Nef T, Mihelj M, Riener R. ARMin: a robot for patient-cooperative arm therapy. Med Biol Eng Comput. 2007; 45:887-900.

41. Cai LL, Fong AJ, Otoshi CK, et al. Implications of assist-as-needed robotic step training after a complete spinal cord injury on intrinsic strategies of motor learning. The Journal of neuroscience : the official journal of the Society for Neuroscience. 2006;26:10564-8. 
[NO STYLE for: Cai 2005].

43. Swinnen E, Duerinck S, Baeyens JP, Meeusen R, Kerckhofs E. Effectiveness of robot-assisted gait training in persons with spinal cord injury: a systematic review. J Rehabil Med. 2010;42:520-6.

44. Alcobendas-Maestro M, Esclarín-Ruz A, Casado-López RM, et al. Lokomat Robotic-Assisted Versus Overground Training Within 3 to 6 Months of Incomplete Spinal Cord Lesion: Randomized Controlled Trial. Neurorehabil Neural Repair. 2012.

45. Shadmehr R, Mussa-Ivaldi FA. Adaptive representation of dynamics during learning of a motor task. J Neurosci. 1994;14:3208-24.

46. Patton JL, Stoykov ME, Kovic M, Mussa-Ivaldi FA. Evaluation of robotic training forces that either enhance or reduce error in chronic hemiparetic stroke survivors. Experimental brain research Experimentelle Hirnforschung Expérimentation cérébrale. 2006;168:368-83.

47. Perez MA, Lungholt BK, Nyborg K, Nielsen JB. Motor skill training induces changes in the excitability of the leg cortical area in healthy humans. Experimental brain research Experimentelle Hirnforschung Expérimentation cérébrale. 2004;159:197-205.

48. Meister I, Krings $\mathrm{T}$, Foltys $\mathrm{H}$, et al. Effects of long-term practice and task complexity in musicians and nonmusicians performing simple and complex motor tasks: implications for cortical motor organization. Human brain mapping. 2005;25:345-52.

49. Huang VS, Krakauer JW. Robotic neurorehabilitation: a computational motor learning perspective. J Neuroeng Rehabil. 2009;6:5.

50. Ellis MD, Sukal-Moulton T, Dewald JP. Progressive shoulder abduction loading is a crucial element of arm rehabilitation in chronic stroke. Neurorehabilitation and neural repair. 2009;23:862-9.

51. Raiss $P$, Rettig $O$, Wolf $S$, Loew M, Kasten P. [Range of motion of shoulder and elbow in activities of daily life in 3D motion analysis]. Z Orthop Unfall. 2007;145:493-8.

52. Harris JE, Eng JJ. Strength training improves upper-limb function in individuals with stroke: a metaanalysis. Stroke; a journal of cerebral circulation. 2010;41:136-40. 
53. Kwakkel G, Wagenaar RC, Twisk JW, Lankhorst GJ, Koetsier JC. Intensity of leg and arm training after primary middle-cerebral-artery stroke: a randomised trial. Lancet. 1999;354:191-6.

54. Biernaskie J, Corbett D. Enriched rehabilitative training promotes improved forelimb motor function and enhanced dendritic growth after focal ischemic injury. The Journal of neuroscience : the official journal of the Society for Neuroscience. 2001;21:5272-80.

55. Wolfe CD, Tilling K, Rudd AG. The effectiveness of community-based rehabilitation for stroke patients who remain at home: a pilot randomized trial. Clinical rehabilitation. 2000;14:563-9.

56. Stuart M, Benvenuti F, Macko R, et al. Community-based adaptive physical activity program for chronic stroke: feasibility, safety, and efficacy of the Empoli model. Neurorehabilitation and neural repair. 2009;23:726-34.

57. Saposnik G, Teasell R, Mamdani M, et al. Effectiveness of virtual reality using Wii gaming technology in stroke rehabilitation: a pilot randomized clinical trial and proof of principle. Stroke; a journal of cerebral circulation. 2010;41:1477-84.

58. Flynn S, Palma P, Bender A. Feasibility of using the Sony PlayStation 2 gaming platform for an individual poststroke: a case report. J Neurol Phys Ther. 2007;31:180-9.

59. Redzuan NS, Engkasan JP, Mazlan M, Abdullah SJ. Effectiveness of a video-based therapy program at home after acute stroke: a randomized controlled trial. Archives of physical medicine and rehabilitation. 2012.

60. Schultz W. Behavioral dopamine signals. Trends in neurosciences. 2007;30:203-10.

61. Hosp JA, Pekanovic A, Rioult-Pedotti MS, Luft AR. Dopaminergic projections from midbrain to primary motor cortex mediate motor skill learning. The Journal of neuroscience : the official journal of the Society for Neuroscience. 2011;31:2481-7.

62. Molina-Luna K, Pekanovic A, Rohrich S, et al. Dopamine in motor cortex is necessary for skill learning and synaptic plasticity. PloS one. 2009;4:e7082. 
63. Scheidtmann K, Fries W, Müller F, Koenig E. Effect of levodopa in combination with physiotherapy on functional motor recovery after stroke: a prospective, randomised, double-blind study. Lancet. 2001;358:787-90.

64. van Wijck F, Knox D, Dodds C, Cassidy G, Alexander G, MacDonald R. Making music after stroke: using musical activities to enhance arm function. Ann N Y Acad Sci. 2012;1252:305-11.

65. Caurin GA, Siqueira AA, Andrade KO, Joaquim RC, Krebs HI. Adaptive strategy for multi-user robotic rehabilitation games. Conference proceedings : Annual International Conference of the IEEE Engineering in Medicine and Biology Society IEEE Engineering in Medicine and Biology Society Conference. 2011;2011:1395-8.

Figure 1: Potential conceptual framework for achieving well-founded evidence in neurorehabilitation 